\title{
VEINCTR-N, an Immunogenic Epitope of Fas (CD95/Apo-I), and Soluble Fas Enhance T-cell Apoptosis in vitro. II. Functional Analysis and Possible Implications in HIV-1 Disease
}

\author{
Franco Silvestris, Paola Cafforio, Marco Tucci, Annalisa Del Prete, \\ and Franco Dammacco
}

\author{
Department of Biomedical Sciences and Human Oncology, University of Bari, \\ Section of Internal Medicine, Bari, Italy
}

Accepted April 15, 2000.

\begin{abstract}
Background: Recent studies indicate that soluble Fas (sFas) may modulate T-cell apoptosis, since it inhibits Fas-ligand (Fas-L)-mediated cytotoxicity in vitro. Here, we explored whether the soluble receptor and its major immunogenic domain, namely VEINCTR-N, interfered with apoptosis of $\mathrm{T}$ cells from human immunodeficiency virus-type 1 (HIV$1)^{+}$subjects showing serum elevations of both the soluble receptor and anti-Fas antibodies, and with that of several T-cell lines.

Materials and Methods: Both proliferation and apoptosis extent of $\mathrm{T}$ cells from $16 \mathrm{HIV}^{-\mathrm{I}^{+}}$ patients showing serum anti-VEINCTR-N immunoglobulin G (IgG) and 15 controls were tested after incubation with sFas and three 8-mer peptides of its first consensus sequence that included VEINCTR-N. Several cell lines were also investigated by flow cytometry for their expression of $\mathrm{Ki}-67$, the APO2.7-related mitochondrial protein, and the annexin-V. In addition, we evaluated the expression of Fas-L and caspases FLICE, CPP32 and ICE either by flow cytometry, immunoblotting, and/or reverse transcription polymerase chain reaction (RT-PCR).
\end{abstract}

Results: Cell proliferation in cultures from both patients and controls was affected significantly by sFas and VEINCTR-N. However, a prevalent increase of the subdiploid DNA-containing cell population occurred within these cultures. Similarly, Jurkat, CEM cells, and a mouse WR19L transformant overexpressing native human Fas underwent prompt apoptosis, which was detected as enlargement of APO2.7-reactive and annexin-V-positive populations. By exploring the Fas pathway in Jurkat cells, we found that both apoptosis inducers acted through Fas, since Fas-L, as well as CPP32 and FLICE were activated. By contrast, ICE was up-regulated only in control cells treated with tumor necrosis factor $\alpha(\mathrm{TNF} \alpha)$. Conclusions: These data suggest that the soluble molecular forms of Fas prime cell death in Faspositive cells. Therefore, the shedding of high amounts of sFas in HIV-1 disease is possibly entrusted with amplification of the death execution program by cells functionally exhausted and committed to die. It is conceivable that the appearance of anti-Fas antibodies reflects an attempt by the immune system to neutralize these effective forms of the receptor and its structurally degraded domains, such as VEINCTR-N.

\section{Introduction}

Antibodies to Fas (CD95/Apo-I) that have an agonist effect on apoptosis of activated $\mathrm{T}$ cells

Address correspondence and reprint requests to: Franco Silvestris, M.D., DIMO, University of Bari, Section of Internal Medicine, P.za Giulio Cesare, 11, 70124, Bari, Italy. Phone: +39080-547-8771; Fax: +39080-547-8820; E-mail: f.silvestris@dimo.uniba.it during human immunodeficiency virus-type 1 (HIV-1) infection have been described by ourselves (1) and others (2). These antibodies play a role in the depletion of $\mathrm{CD}^{+}$lymphocytes that define its progression to AIDS. Their occurrence is usually paralleled by severe lymphopenia (3). They were previously thought to be elicited by molecular mimicry of the gp120 
V3 loop (4) exhibiting VEINCTR-N, a short domain also shared by the extracellular portion of Fas $(5,6)$. Our recent data, however, suggest a peculiar conformational immunogenicity of this epitope (7). It is structurally located within the first consensus sequence of members of the tumor necrosis factor (TNF) receptor family $(5,8)$ and shows multiple disulphide bonds. In addition, significant levels of immunoglobulin G (IgG) to VEINCTR-N have been found to correlate with serum elevations of soluble Fas (sFas) (7). Further work from different groups of investigators provided evidence that serum titers of sFas may be increased in early $(2,9)$, as well as in advanced, HIV-1 infection $(10,13)$.

The shedding of membrane receptors by activated $\mathrm{T}$ cells has been stressed when describing the serologic increase of soluble forms of human leucocyte antigen (HLA) class I and II molecules $(14,15)$; $T$ cell receptor (TCR) multiple chains (16); members of the TNF receptor family, including Fas and Fas-ligand (Fas-L) in a number of inflammatory diseases, allografts, autoimmune diseases (17); and HIV-1 infection $(18,19)$. Most experimental data indicate that, although several soluble receptors may even occur in healthy individuals $(15,20)$, increased serum levels are associated prevalently with their persistent activation in these diseases. Clinical studies have shown that, in parallel with both chronic activation and deregulated apoptosis in patients with systemic lupus erythematosus (SLE) or other autoimmune disorders, significant elevations of SFas and SFas-L are detectable, in particular during the active stages $(17,21)$, and in relation to the HLA status (22).

The physiologic function(s) of these soluble receptors is not completely clarified. Enhanced serum sFas-L, indeed, has been proposed as a disease-marker in certain lymphoproliferative disorders of the cytotoxic cell lineage (24); whereas, the increase of sFas parallels progression in several B- and T-cell leukemias $(25,26)$. Additional studies propose that the membraneshedding of Fas by activated cells could imply a molecular mechanism to prevent their apoptosis by neutralizing Fas-L of cytotoxic cells (27). This role of apoptosis blocker (28) also has been attributed to splicing variants of sFas, which are secreted by phytohemagglobinin (PHA)-activated mononuclear cells from healthy individuals and by human T-cell lines. Apoptosis blockers interfere with their apoptosis induced in vitro by the prototypic agonist anti-Fas monoclonal antibody (MoAb) from clone CH-11 (33).
However, the role of the sFas and sFas-L in HIV-1 disease is still controversial. Elevated serum levels of both receptors draw attention to the substantial deregulation of T-cell apoptosis during infection $(30,31)$. Even so, sFas in sera from HIV-1-infected children with no evidence of progression to AIDS is suspected to inhibit the apoptosis of $\mathrm{CD}^{+}$cells promoted by antiHIV-1-specific cytotoxic T lymphocytes (CTLs), thus interpreting their stable values during early disease (9). Conversely, similar elevations of sFas have been correlated with the massive T-cell apoptosis observed in advanced infection $(10,13)$, suggesting that sFas is somehow implicated in the consistent cell death of exhausted cells. It is conceivable that cells committed to die by apoptosis as a result of their chronic activation during infection solubilize Fas with the potential effect of shedding the death signal and amplifying the execution program.

We previously interpreted the humoral response to VEINCTR-N in advanced disease as a potential result of the high levels of circulating sFas (7). The present study investigates the effect of sFas and its domains related to VEINCTR-N, on T-cell proliferation and apoptosis. Our results indicate that $\mathrm{sFas}$ and its immunogenic epitope directly prime $\mathrm{T}$ cells from HIV-1-infected patients and Fas-positive T-cell lines for apoptosis. Thus, our data emphasize that $\mathrm{sFas}$ should be regarded as an amplifier, rather than a blocker of apoptosis.

\section{Materials and Methods}

\section{Peripheral T-cell Cultures and Cell Lines}

Sixteen HIV-1 $1^{+}$patients with serum positivity to VEINCTR-N and 15 uninfected individuals provided blood samples following the approval of the study by the ethical committee of the University of Bari Medical School. Peripheral $\mathrm{T}$ lymphocytes were prepared by Ficoll-Hypaque centrifugation, removal of adherent cells, incubation with sheep red cells, and subsequent gradient centrifugation to discharge the non-Erosetting cells. Phenotyping was performed by flow cytometry, using a panel of fluorescein isothiocyanate (FITC) or phycoerythrin (PE)conjugated MoAbs to CD3, CD4, and CD8 markers in a fluorescence-activating cell sorting (FACScan $\left.{ }^{\circledR}\right) \quad$ (Becton-Dickinson, Mountain View, CA). Control cell suspensions were incubated with nonspecific mouse IgG; whereas, Tcell enrichment was evaluated by gating each 
cell preparation by both FITC-anti-CD45 and PE-anti-CD14 (Becton-Dickinson), which revealed less than $1.2 \%$ monocyte contamination. Each analysis included a total of 10,000 events. Aliquots were used to set up T-cell cultures from both patients and controls. T-cell cultures were started in plates at $1 \times$ $10^{6} / \mathrm{ml}$ in RPMI- 1640 plus $10 \%$ fetal calf serum, $10 \mu \mathrm{g} / \mathrm{ml}$ PHA and interleukin-2 (IL-2), and maintained for up to $72 \mathrm{hr}$ in the presence of two 8-mer synthetic peptides resembling the flank regions of VEINCTR-N (7), namely peptide (pept.) \#1 (CDEGHGLE) and pept. \#2 (TKCRCKPN), in addition to VEINCTR-N itself, and native human sFas (Alexis Corporation, San Diego, CA). The synthetic peptides, as well as the recombinant sFas, were filtered to avoid any contamination and were endotoxinfree as a result of the purification procedure by high performance liquid chromatography (HPLC) (7). Each peptide was separately added to cell cultures at various concentrations $(10,25$, and $50 \mu \mathrm{g} / \mathrm{ml})$ to measure the dosedependent effect; whereas, sFas was used at lower amounts $(0.1,1,5$, and $10 \mu \mathrm{g} / \mathrm{ml})$. Parallel experiments evaluated the effect of both Fasrelated peptides and the full-length sFas on Faspositive cell lines that included both Jurkat and CEM cells (American Type Culture Collection (ATCC), Manassas, VA) as models of human T cells of clonal origin, and the mouse WR 19L cell transformant overexpressing Fas (32). As Fasnegative cell controls, we used both $\mathrm{K} 562$ and Daudi, and the native WR19L as human and mouse cell lines, respectively. Several of them were also used in subsequent tests to avoid the potential heterogeneity of T-cell cultures from both patients and donors, since they were not clonally obtained.

\section{Evaluation of Proliferation and Apoptosis}

Aliquots of cells were recovered from the peptide- and sFas-stimulated cultures after 24, 48, and $72 \mathrm{hr}$ of incubation and their proliferation and apoptosis were measured. Suitable control cultures were also provided by unstimulated cell suspensions. In addition, the sFasstimulated cultures were paralleled by control cell preparations additionated with sFas preincubated for 90 min, with the mouse IgG antiFas MoAb from clone ZB4 (Immunotech, Marseille, France) at $10 \mu \mathrm{g} / \mathrm{ml}$, as an attempt to neutralize its binding. Proliferation was determined by evaluating both the ${ }^{3} \mathrm{H}$-thymidine uptake and Ki67 antigen expression in cultures and cell lines. $10^{5}$ cells from each preparation were incubated overnight in the presence of ${ }^{3} \mathrm{H}$-thymidine (7400 Bq per well). The proliferation rate was assessed with a $\beta$-counter (Beckman, Palo Alto, CA) and calculated according to previously standardized experiments as a percentage of ${ }^{3} \mathrm{H}$-thymidine incorporation or inhibition of proliferation (31). A parallel cytofluorimetric assay investigated the expression of Ki67 by a FITC-conjugated MoAb (MIB-1 clone; Immunotech) after treatment with $50 \mu \mathrm{g} / \mathrm{ml}$ digitonin (Sigma, St. Louis, MO) to improve the cell membrane permeability. Lastly, Ki67 expression on viable cells gated by their scatter parameters, was analyzed by the Cell Quest program in the FACScan ${ }^{\circledR}$ (Becton-Dickinson).

Apoptosis was initially assessed by cytofluorimetric measurement of cell populations with subdiploid DNA peak by propidium iodide (PI) as described (31). Aliquots of cell preparations were also examined in parallel with the APO2.7 MoAb to a $38 \mathrm{kDa}$ mitochondrial protein, which is regarded as an early apoptosis marker, since viable cells were negative or weakly positive (33). Its expression was assessed by flow cytometry using the permeabilizing protocol with digitonin and the PEconjugated APO2.7 (Immunotech). In some instances, apoptosis was also evaluated by the terminal deoxynucleotidyl transferase dUTP nick end labeling (TUNEL; Promega, Madison, WI), and by the annexin-V fluorescence assay (Boehringer-Mannheim, Milan, Italy).

\section{Detection and Analysis of Cytoplasmic Free Calcium}

The degree of cell activation was also determined by analysis of cytoplasmic free $\mathrm{Ca}^{2+}$ in response to stimulation by either sFas or its peptides, according to Vanderberghe and Ceuppens (34), with fluo-3 as the fluorescent indicator of $\mathrm{Ca}^{2+}$. Briefly, Jurkat, WC8, and WR19L cells were pretreated for $1 \mathrm{hr}$ with fluo-3 at a final concentration of $4 \mu \mathrm{M}$. They were then washed three times, resuspended in a N-2-hydroxyethyl piperazine-N-2-ethanesulfonic acid (HEPES)buffered solution, at $\mathrm{pH} 7.4$, containing $1 \mathrm{mM}$ $\mathrm{CaCl}_{2}, 0.5 \mathrm{mM} \mathrm{MgCl}$, and bovine serum albumin (BSA), and stimulated with sFas and peptides, and with the CHIl anti-Fas MoAb (Immunotech) as control, for 15, 45, and $75 \mathrm{~min}$. Furthermore, the suspensions were analyzed discontinuously in their events in the FACScan ${ }^{\circledR}$ 
by the Cell Quest software (Becton-Dickinson), and the data were compared with the unstimulated control preparations.

\section{Measurement of Fas-L Cell Expression and Release}

The expression of Fas- $L$ in cell preparations was improved by treatment with EDTA to inhibit the shedding of Fas-L by cell membranes (35); whereas, its release in the supernatants was assessed by ELISA (36). Cells were first incubated with the biotin-conjugated anti-Fas-L MoAb from NOK-1 clone (PharMingen, San Diego, CA) and then treated with streptavidin-FITC (Sigma) prior to their cytofluorimetric analysis in the FACScan ${ }^{\circledR}$. Furthermore, we measured the expression of Fas-L mRNA in cell lines stimulated with both VEINCTR-N and sFas by molecular biology tests (37). mRNA was isolated by the guanidium thiocyanate-cesium chloride procedure (Invitrogen, Celbio, Pero, Italy), and transcribed into first-strand cDNA with the Boehringer-Mannheim kit. The Fas-L wild-typespecific primers were designed in relation to the known gene structure as follows: 5'-GCC CAA GCT TGA AGC AGC CCT-3' (FW), and 5'-TGC TGT GTG CAT CTG GCT GGT AGA-3' (RV) related to exon-2 of the gene. Both primers and cDNA from cell lines were added to the polymerase chain reaction (PCR) mixture (Perkin Elmer Biosystems, Foster City, CA), with subsequent amplification in a thermal cycler for $35 \mathrm{cy}$ cles $\left(30 \mathrm{sec}\right.$ at $94^{\circ} \mathrm{C} ; 30 \mathrm{sec}$ at $65^{\circ} \mathrm{C}$; and $30 \mathrm{sec}$ at $72^{\circ} \mathrm{C}$ ). The Fas-L PCR product was visualized on agarose gel with ethidium bromide. It was then measured by evaluating the bands as "trace quantity value" optical density (O.D. $\times$ mm of each band) with the Quantity-One 4.3 software in the Fluor-S MultiImager gel analyzer (BioRad Labs, Hercules, CA). For semiquantitative analysis, graded amounts of cDNA obtained from the same tube were used in parallel PCR experiments to obtain a linear reference curve; $\beta$-actin also was included as internal control (FW: 5'-GAC CAT CAC GAT GCC AGT GGT A-3'; RV: 5'-GAT CAT GGA TGA TGA TAT CGC- $\left.3^{\prime}\right)$. Lastly, the ELISA measuring the secretion of Fas-L in the supernatants from the same cell preparations was optimized by using two MoAbs to different epitopes of Fas-L, namely NOK-1 and NOK-2 (PharMingen). The test was completed as previously described (36).

\section{Evaluation of Caspase Activation}

We also explored by different approaches the activation of three caspases to determine whether apoptosis induced by VEINCTR-N and sFas was promoted by activation of the membrane-bound Fas. Cytosolic extracts were prepared by homogenizing cell pellets in 10 mM HEPES/KOH (pH 7.4), 2mM EDTA, 0.1\% (3-[(3-cholamidopropyl) dimethylammonio]-lpropane-sulfonate (CHAPS), 5mM DL-Dithiothreitol (DTT), l mM phenyl-methylsulphonylfluoride, $10 \mu \mathrm{g} / \mathrm{ml}$ pepstatin A, $20 \mu \mathrm{g} / \mathrm{ml}$ leupeptin and $10 \mu \mathrm{g} / \mathrm{ml}$ aprotinin, and recovering the supernatant after centrifugation at $14,000 \times \mathrm{g}$ (Sigma, St. Louis, MO, USA). The extracts were run in SDS-PAGE, blotted in nitrocellulose, blocked with $2 \%$ BSA in phosphate-buffered saline (PBS) plus $0.05 \%$ Tween-20, and separately incubated overnight at $4^{\circ} \mathrm{C}$ with a mouse MAb to caspase 8 (FLICE; Biosource, International, Camarillo, CA), and rabbit polyclonal antisera to caspase 3 (CPP32) and caspase 1 (ICE; Biosource). Both polyclonal antisera were described by the manufacturer as able to detect the proenzymatic form, as well as the cleaved subunits, of relative caspases. The test was subsequently completed with the peroxidase-coupled anti-mouse and anti-rabbit IgG antisera, respectively. Both proenzymatic caspases and subunits were revealed on blots by enhanced chemiluminescence, according to the manufacturer's instructions (Amersham International, Buckinghamshire, England).

A second method measuring caspases activation included a colorimetric assessment of their cleaved subunits in the cytosolic extracts from Jurkat cells incubated for $48 \mathrm{hr}$ with those apoptosis inducers. We used specific substrates for CPP32 and ICE, according to the manufacturer's protocol (Alexis). Briefly, $100 \mu \mathrm{l}$ of cell lysates in reaction buffer (100 mM HEPES pH 7.5, $10 \%$ sucrose, $0.1 \%$ CHAPS, $10 \mathrm{mM}$ DTT, $0.1 \mathrm{mg} / \mathrm{ml}$ ovalbumin) were incubated in 96-well plate for $3 \mathrm{hr}$ at $37^{\circ} \mathrm{C}$, with $50 \mu \mathrm{M}$ of p-Nitroanilide (pNA)conjugated-specific four-amino-acid substrates for caspase 3 and l (DEVD-pNA and YVADpNA, respectively). Each determination was performed in triplicate and relative absorbance was measured at $405 \mathrm{~nm}$ in a (Benchmark) microplate reader (Bio-Rad Labs, Hercules, CA).

Molecular analysis of caspase expression was also completed by RT-PCR measurement of relative mRNA. In addition to Jurkat cell preparations treated with sFas, VEINCTR-N, and $\mathrm{CHIl} \mathrm{MoAb}$ as positive control of the Fas 
activation pathway, we included a parallel cell suspension incubated with TNF $\alpha$ at the functional dose of $10 \mathrm{ng} / \mathrm{ml}$ as a positive control to look for any discrepancy in expression between the Fas and the TNF $\alpha$ pathways. The mRNA from Jurkat cells incubated overnight with CH11, sFas, VEINCTR-N, or TNF $\alpha$, and from untreated control cells was then amplified in a thermal cycler by the RT-PCR method. The primers were designed according to the gene structure of each caspase (38-40) as follows: ICE (casp. 1) 5'-GCA CAC GTC TTG CTC TCA TTA TCT G-3' (FW), and 5'-GGC TGC TCA ADT GAA AAT CGA ACC-3' (RV); CPP32 (casp. 3) 5'-TGG TAC AGA TGT CGA TGC AGC-3' (FW), and 5'-TGC CAC AGT CCA GTT CTG TAC C-3' (RV); and FLICE (casp. 8) 5'-TGA GCT GAC ATC TCA GTT CAC TGG T-3' (FW), and 5'-TGT GAA AGT AGG CTG AGG CAT CTG-3' (RV). The amplification was completed by standard procedures using $35 \mathrm{cy}$ cles $\left(60 \mathrm{sec} 94^{\circ} \mathrm{C} ; 60 \mathrm{sec} 60^{\circ} \mathrm{C}\right.$; and $\left.60 \mathrm{sec} 72^{\circ} \mathrm{C}\right)$ and semiquantitative analysis of mRNA on the agarose gel was assessed as the trace quantity value for each determination by the Fluor-S gel analyzer (Bio-Rad Labs). Graded amounts of cDNA of each caspase were also amplified to provide relative reference curves in addition to the $\beta$-actin measurement.

\section{Statistical Analysis}

Mean values of cellular marker expression and proliferation between groups were compared with Student's $t$-test. The distribution of subdiploid DNA content in both stimulated and unstimulated cultures was also assessed in a few instances by the Wilcoxon test as a nonparametric method.

\section{Results \\ Effect of sFas and Its Peptides on T-cell Culture Proliferation and Apoptosis}

The first set of experiments addressed the question whether VEINCTR-N, its contiguous 8-mer stretches, and sFas interfered with the replication of $\mathrm{T}$ cells. The proliferation rate of T-cell cultures stimulated with these protein fragments was compared with the ${ }^{3} \mathrm{H}$-thymidine incorporation of unstimulated cultures from both patients and controls whose individual values were considered as reference levels of proliferation $(100 \%$ of ${ }^{3} \mathrm{H}$-thymidine uptake). In preliminary experi- ments, we assessed the dose-response kinetics by using different amounts of these stimulators. An appreciable response was recorded with a concentration of $25 \mu \mathrm{g} / \mathrm{ml}$, though $50 \mu \mathrm{g} / \mathrm{ml}$ of each peptide produced the greatest effect. By contrast, sFas was found to optimize its response at $5 \mu \mathrm{g} / \mathrm{ml}$. Therefore, we adopted these concentrations and Figure 1 shows the time-dependent results. As depicted, a major suppression was observed after $48 \mathrm{hr}$ (Fig. 1A). VEINCTR-N, however, induced a higher degree of inhibition at a magnitude similar to sFas, since the mean values of ${ }^{3} \mathrm{H}$-thymidine uptake dropped to about $40 \%$. A lower, though significant $(p<0.1)$, suppression (about 50\%) also occurred in cultures treated with pept. \#2; whereas, pept. \# 1 induced a lower inhibitory effect, even after $72 \mathrm{hr}$ of incubation. We observed a slightly different response in cultures from uninfected individuals. Almost all cell preparations but those sFastreated, were insensitive to the peptides and showed a minor inhibition, even with the progression of the incubation. By contrast, the mean values of suppression obtained in sFas-incubated cultures revealed a significant inhibition $(p<0.03)$, compared with those induced by the peptides, since the inhibitory effect was nearly equivalent to those recorded in the suppressed cultures from patients. However, the sFas inhibited by preincubation with ZB4 MoAb was revealed to be ineffective for inducing a similar extent of suppression in both groups of cultures.

sFas- and peptide-incubation also induced a variable extent of apoptosis. A prevalent increase was observed in cultures incubated with both VEINCTR-N and sFas. This effect was persistently evident after $48 \mathrm{hr}$ in most patient cell preparations and to a lesser degree in those from the controls. The subdiploid cell population was almost doubled following incubation with VEINCTR-N or sFas. Figure 1B shows the cytofluorimetric PI staining of the apoptotic cells in representative patterns from patient \#11 and a normal donor (\#7). As can be seen, both VEINCTR-N and sFas induced a remarkable increase of the Ml peak, which included the subdiploid-DNA-containing cells in either the patient (upper panels) or the control (lower panels). Data from the other patients and controls revealed a prevalent pattern of amplification of this population in response to either sFas or VEINCTR-N, with significant differences in increments $(p<0.02$ in both groups). By contrast, no appreciable variation of the extent of apoptosis was 
A)

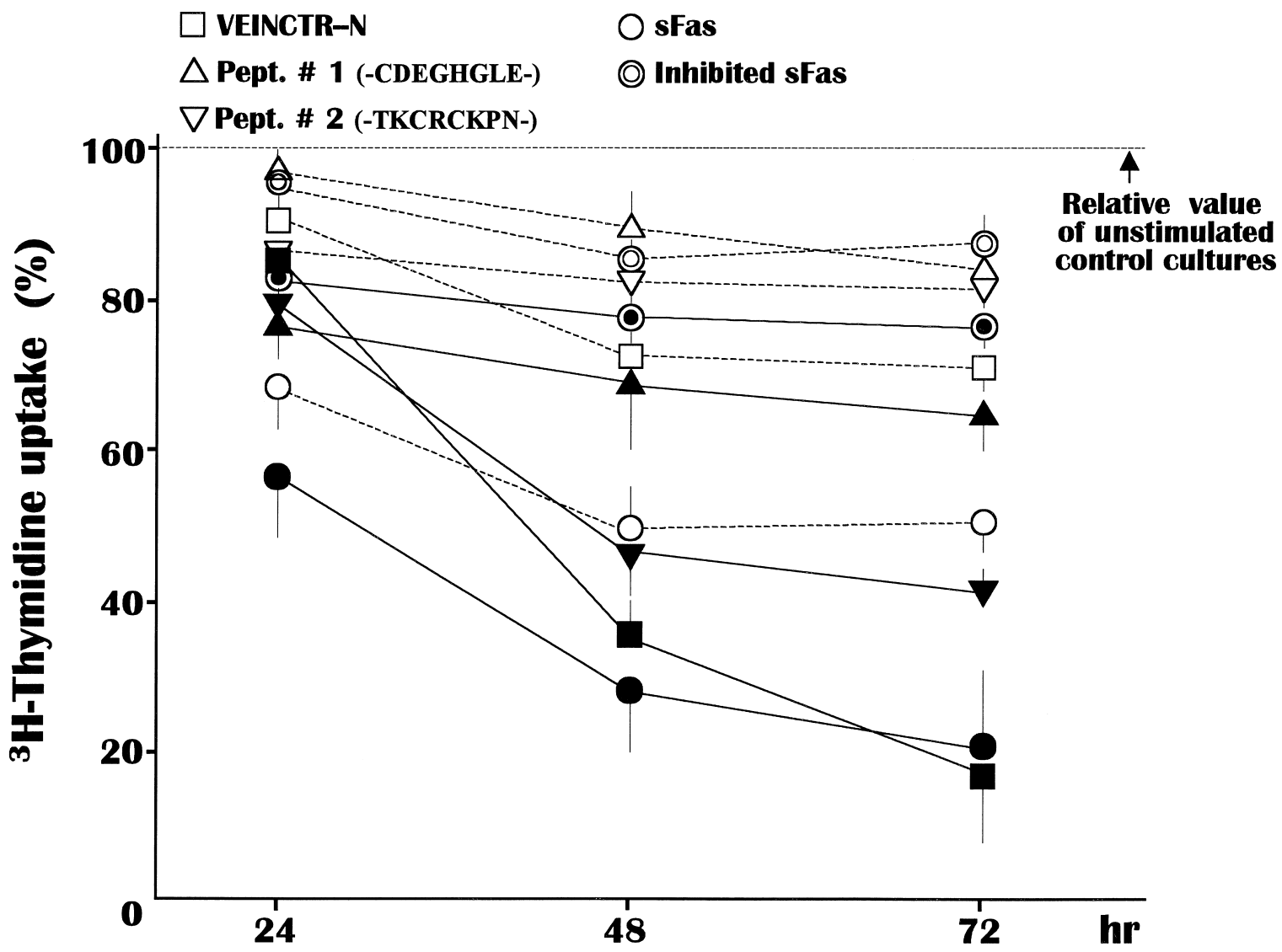

Fig. 1. Suppression of peripheral $\mathrm{T}$ cells by soluble molecular forms of Fas, including the full-length receptor (sFas), and sequential 8-mer peptides structurally related to its first consensus sequence including VEINCTR-N, an immunogenic epitope. (A) Prevalent inhibition of the proliferative rate was observed after $48 \mathrm{hr}$ in T-cell cultures from 16 human immunodeficiency virus-type 1 (HIV-1)-infected individuals (full symbols) selected from a group of patients with serum elevations of both anti-VEINCTR-N immunoglobulin G (IgG) and soluble Fas (sFas), and increased extent of T-cell apoptosis (7). Inhibition of ${ }^{3} \mathrm{H}$-thymidine uptake was significant in cultures treated with either sFas or VEINCTR-N $(p<0.02$ in all instances), and in those with pept. $\# 2(p<0.1)$, compared with relative control unstimulated cultures whose values of ${ }^{3} \mathrm{H}$-thymidine uptake were referred as $100 \%$ of proliferation.

recorded in cultures incubated with either pept. \# 1 or \#2.

Fas-positive Cell Lines are Sensitive to VEINCTR-N and sFas-mediated Suppression

Since the patients and control cell cultures were not clonally expanded and included heterogeneous $\mathrm{T}$ cells at various differentiation steps,
Control T-cell cultures from 15 uninfected subjects (empty symbols) were inhibited prevalently by sFas, though to a lesser degree. Such a suppressive effect of sFas was abolished in control cultures by its preincubation with ZB4 MoAb. Values are expressed as percentages of ${ }^{3} \mathrm{H}$-thymidine uptake. (B) Cytofluorimetric patterns of apoptosis induction by both sFas and VEINCTR-N in peripheral T cells from an HIV-1-infected patient (upper panels) and a normal donor (lower panels), measured as variation of M1, namely the subdiploid DNA-containing cell population, following propidium iodide staining. A significant increase of Ml occurred at $48 \mathrm{hr}$ of culture in cells treated with either sFas or VEINCTR-N, compared with untreated control cells ( $p<0.02$ in both groups of experiments). By contrast, pept. \# 1 and \#2 failed to induce appreciable changes in most cell preparations.

we reasoned that optimization of the effect of these soluble inhibitors on clonal models of T-cell lines could emphasize their apoptogenpotential. Therefore, we set up several assays with Jurkat and CEM as Fas-positive human T-cell models, and with K-562 and Daudi as Fas-negative controls. Figure $2 \mathrm{~A}$ shows the effect on the proliferation of these cell lines. Both Jurkat and CEM were significantly affected, 


\section{B) Subdiploid DNA peak variations}
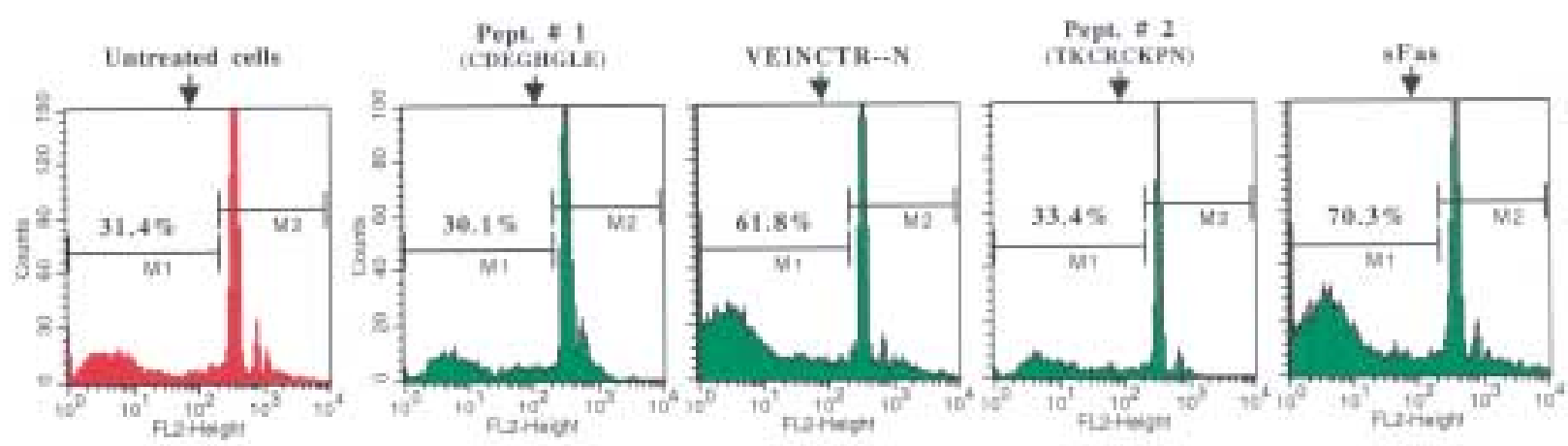

HIV-1 pt. \# II
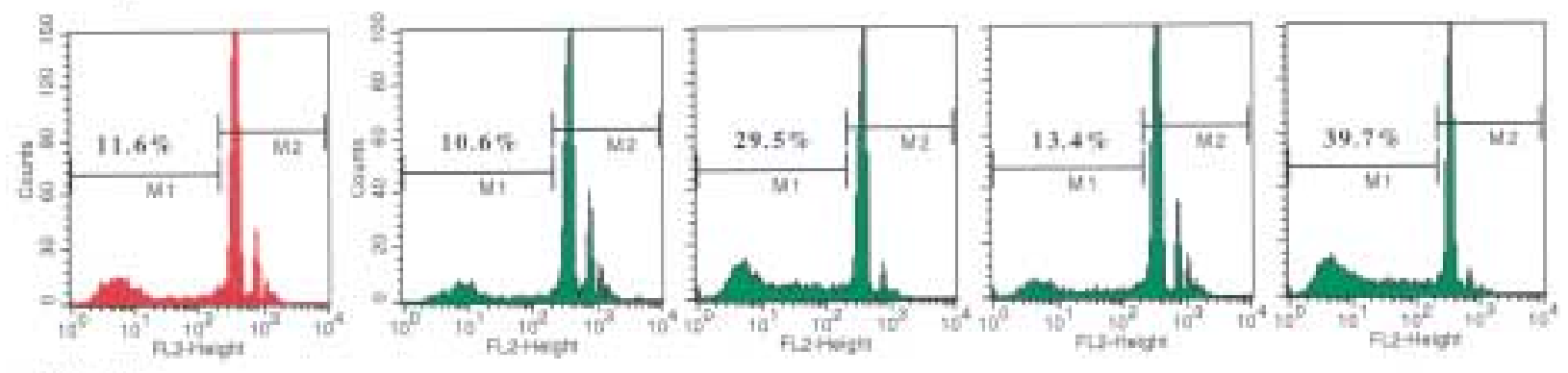

Fig. 1. (Continued)

compared with their control lines. A major suppression was detected in cell preparations incubated with either VEINCTR-N or sFas, whose average inhibition after $48 \mathrm{hr}$ increased to about $60 \%$ and $40 \%$ in Jurkat and CEM cultures, respectively ( $p<0.02$ in both instances). A minor effect was also recorded for pept. \#2, which restrained their proliferation by about $40 \%$ and $30 \%$. Conversely, a minimal inhibition was induced by pept. \#l, as in the patient cultures; whereas, the proliferation of both K-562 and Daudi remained unaltered. These results suggested that the occurrence of Fas on the cell membrane could be essential for down-modulating proliferation in the presence of $\mathrm{sFas}$ and its peptides. However, we also measured their effect on the proliferative extent of WC8, namely the human Fas-transfected mouse lymphoma, and its negative control, WR 19L (32). WC8 was inhibited in the same way by either VEINCTR-N or sFas (Fig. 2B), though to a lesser degree than Jurkat and CEM; whereas, similar to the Fasnegative human cell models, the proliferation of WR19L was not influenced. This finding postulated the hypothesis that the membrane expression of Fas could be involved with driving the suppressive effect of sFas and its functional peptide. To support the suspected agonist effect of sFas, the Fas-positive control cultures treated with the soluble receptor pre-inhibited by ZB4 MoAb were not affected in their proliferative extent.

Further experiments explored whether the decreased uptake of ${ }^{3} \mathrm{H}$-thymidine in the presence of sFas and related peptides was attributable to specific inhibition of proliferation or enhancement of apoptosis by investigating in parallel the expression of both Ki67 and the APO2.7-related mitochondrial antigen. Figure 2C shows the cytofluorimetric pattern of both Jurkat and CEM cells. In both instances, the expression of these markers differed in relation to the presence of sFas or its functional peptides. In control untreated cultures, the Ki67 positive cells, namely M2 populations, showed high values of fluorescence intensity and were more than $50 \%$ as in those supplemented with pept. \#l. However, the mitochondrial protein was scarcely expressed (M2 $<7.5 \%)$. By contrast, incubation with VEINCTR-N lowered the M2 Ki67 peaks to $22.5 \%$ and $20.2 \%$ for the two cell lines, respectively. An analogous effect was also detected in cultures treated with sFas. Conversely, a different pattern of the mitochondrial protein expression was recorded, since VEINCTR-N raised the APO2.7-positive population to $73.1 \%$ and $54.1 \%$ in Jurkat and CEM cells, respectively; whereas, sFas induced a simi- 
lar accretion of this population. Such a significant increase of the APO2.7-reactive antigen $(p<0.03)$ in cells with defective presence of Ki67 suggested that the major effect of sFas and its active peptide was the actual induction of apoptosis, rather than inhibition of T-cell proliferation.

This suggestion was also supported by the demonstration of enhanced levels of annexin- $V$ on the cell membrane in the same cultures maintained up to $24 \mathrm{hr}$. Figure 2D illustrates this cytofluorimetric profile in both Jurkat and CEM cells. We also measured the effect of stimulation by $s F a s$ and related peptides on the annexin- $V$ expression of WC8 cells. Once again, incubation with either VEINCTR-N or sFas dramatically in- creased the relative M2 peaks, namely the cells exposing phosphatidylserine as the effect of membrane disruption by apoptosis. This population was expanded significantly $(p<0.02$ in all instances) in such models of Fas-positive cells, with respect to the relative control untreated cultures. By contrast, the K-562, Daudi and WR19L control lines failed to show an appreciable M2 peak increase (data not shown).

\section{VEINCTR-N and sFas Activate Cytoplasmic $\mathrm{Ca}^{2+}$}

Activation of Jurkat, WC8 and WR19L cells in response to sFas and its peptides also was measured from the variation of their intracellu-

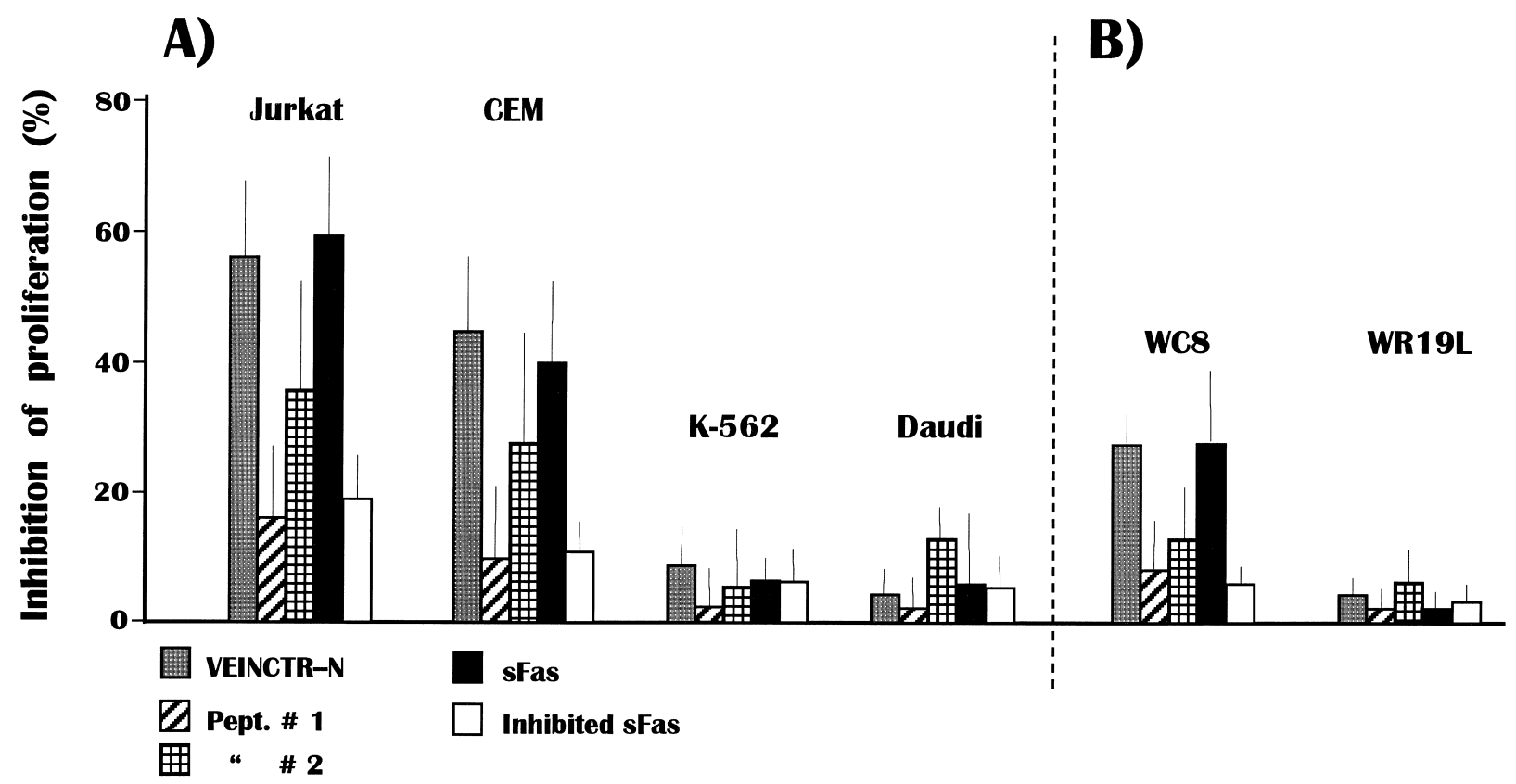

Fig. 2. Percent inhibition of the in vitro proliferative rate in human and mouse $T$-cell lines. Human (A) and mouse (B) T-cell lines were measured by ${ }^{3} \mathrm{H}$-thymidine uptake in the presence of sFas and its soluble peptides. Major inhibition occurred in Jurkat and CEM cells treated with the full-length soluble receptor and with VEINCTR-N, compared with the control untreated cells. Pept. \#2 also moderately inhibited both lines. The human Fas-transfected mouse T-cell lymphoma, WC8, also was suppressed significantly by both sFas and VEINCTR-N; whereas, the proliferation of human (K-562 and Daudi) and mouse (WR 19L)

Fas-negative cell lines was not influenced. The preincubation of sFas with the ZB4 MoAb anti-Fas neutralized its inhibitory effect on cell proliferation. (C) Cytofluorimetric measurement of both Ki67 and APO2.7-related antigens as markers of proliferation and apoptosis, respectively. Jurkat and CEM cells were incubated overnight with the soluble molecular forms of Fas and, then, evaluated in parallel for their expression of both antigens in relation to control cultures. Although the suppressive effect of VEINCTR-N and sFas on both cell lines induced a variable decrease of the Ki67positive population (M2), a significant expansion of the apoptotic subset occurred, since the APO2.7positive M2 extent in both Jurkat and CEM preparations was greatly increased by both inhibitors $(p<0.02$ in all instances). Conversely, pept. \# 1 and \#2 only induced a minor variation of Ki67 expression. (D) Measurement of apoptosis in Fas-positive cell lines by detection of annexin-V. The apoptotic population (M2) was expanded in Fas-positive cell lines of either human (Jurkat and CEM) or mouse (WC8) origin, predominantly in cultures supplemented with VEINCTR-N or with sFas, compared with relative untreated control cultures $(p<0.02)$. The other soluble peptides of Fas resembling the flank regions of VEINCTR-N failed to induce a similar effect. sFas, soluble Fas; pept., peptide. 


\section{C) Fluorescence intracellular marker detection}
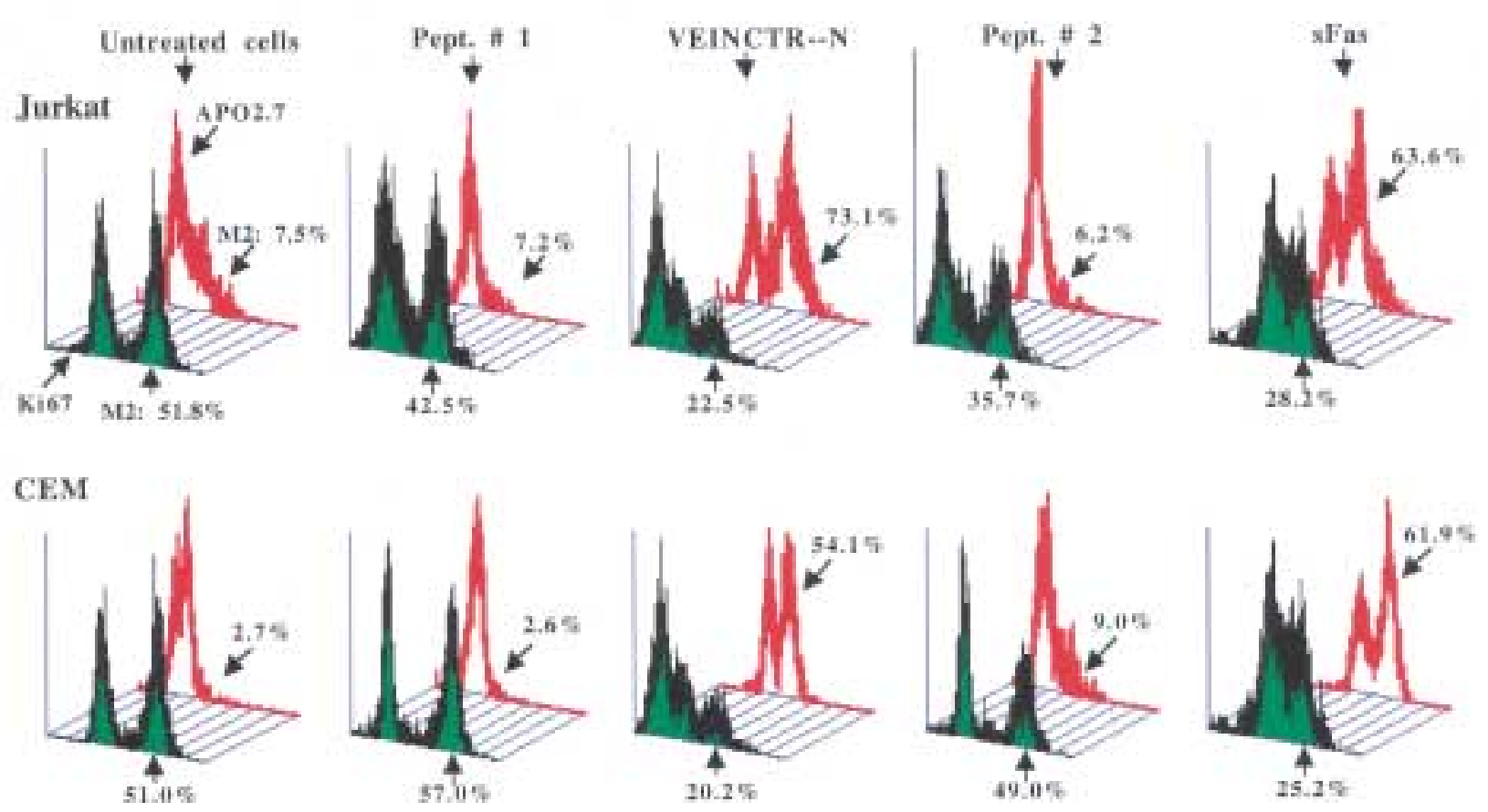

\section{D) Annexin- $V$ detection}
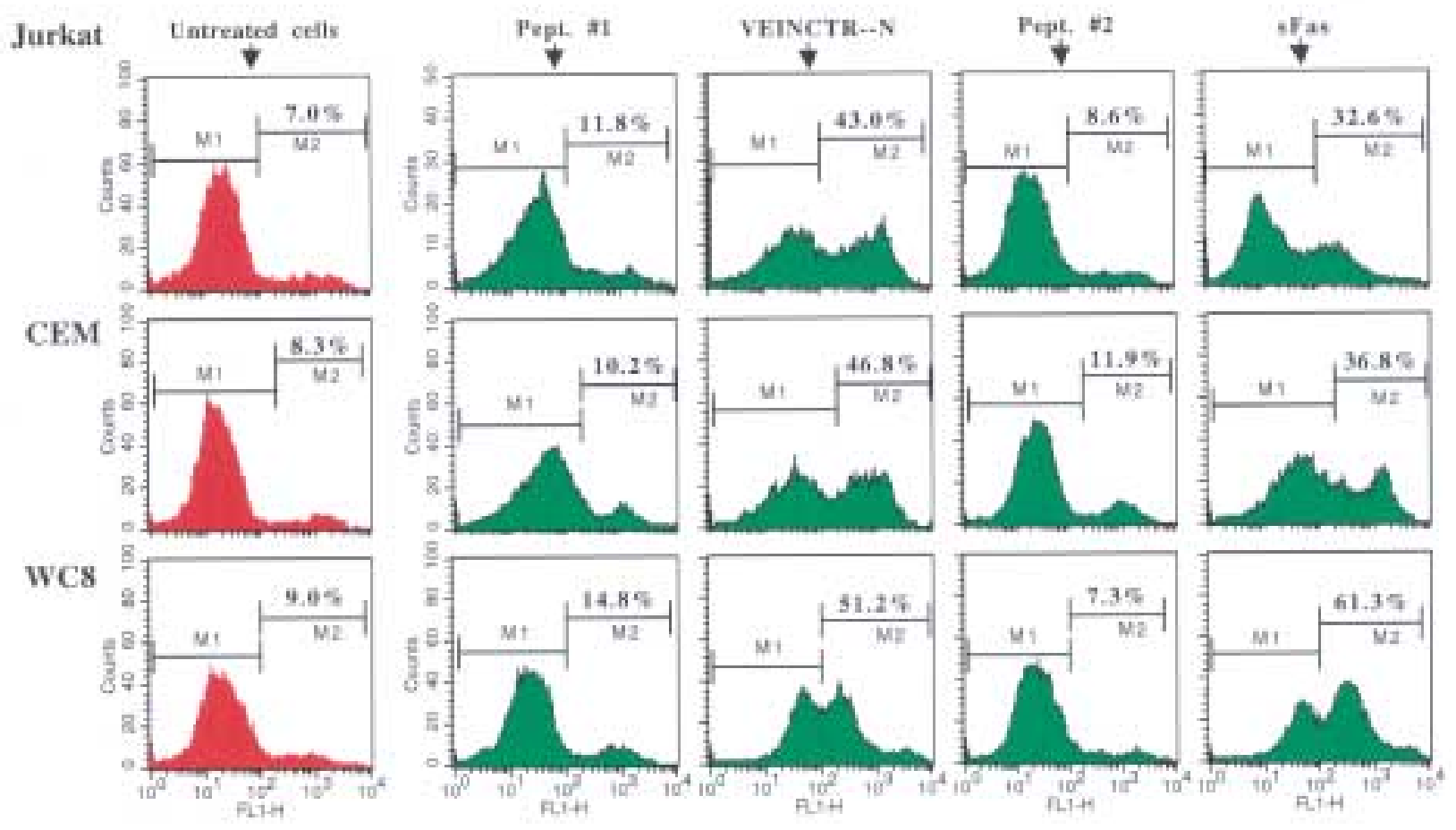

Fig. 2. (Continued) 
lar $\mathrm{Ca}^{2+}$ content. We used fluo-3 staining and evaluated the events in a discontinuous manner. However, comparison of the data at intervals following this treatment provided appreciable differences $30 \mathrm{~min}$ after stimulation. Table 1 shows both the percentage of positive cells to the free cytoplasmic $\mathrm{Ca}^{2+}$ and the mean fluorescence variations. A variable increase of both parameters always was observed, especially in both Fas-positive cell lines incubated with either VEINCTR-N or sFas. Expansion of the subset related to fluo-3-retaining cells was associated with a parallel increase of the fluorescence intensity, whose three-times-higher values were almost equivalent to those obtained with the CHll anti-Fas MoAb. By contrast, the Fas-negative WR19L cells remained unaffected, since no valuable variations of either percentage or fluorescence intensity of positive cells were detected. These data provided definite evidence that $s F a s$ and VEINCTR-N induce an appreciable cell activation, based on the accretion of cytoplasmic free $\mathrm{Ca}^{2+}$ to an extent comparable to that elicited by the agonist anti-Fas MoAb.

\section{Fas-L Expression and Secretion are Influenced by sFas}

Since sFas and VEINCTR-N induced the apoptosis of both human and mouse Fas-positive cell lines, we investigated the involvement of Fas-L with priming the death process in those cells. We measured both the membrane expression of Fas-L by flow cytometry and its release in su- pernatants as the effect of its shedding after overnight incubation with both apoptosis inducers. Preliminary assays showed considerable solubilization of the ligand in culture medium and feeble detection on cell membrane. Therefore, we evaluated both Fas-L expression and secretion in cells cultured in the presence of EDTA to prevent the effect of metalloproteinases (35). In addition, we measured the Fas-L mRNA by RT-PCR in the same cell preparations. Figure $3 \mathrm{~A}$ shows the results of membrane Fas-L expression on Jurkat, WC8, and WR19L cells stimulated by either VEINCTR-N or sFas. Both inhibitors induced an expansion of the Fas- $\mathrm{L}$ positive population, which was increased within the Jurkat and WC8 lines $(p<0.03$ in all instances), in contrast with the stable levels of Fas-L expression in the WR19L line. However, although this percent increment of cells suggested that both stimuli influenced Fas-L expression on many cells, the relative means of fluorescence intensity showed a minimal increase that could mean that EDTA was unable to inhibit complete solubilization of the receptor.

Figure 3B (left graph) shows the results of Fas-L detection and measurement in sFasstimulated Jurkat, WC8, and WR 19L supernatants. The soluble form of Fas significantly increased the solubilization of Fas- $\mathrm{L}$ in supernatants of cultures from Jurkat and WC8 cells, compared with untreated cells $(p<0.02$ in all instances); whereas, its basic secretion by WR 19L remained unaffected. The EDTA-supplemented

Table 1. Measurement of the effect of multiple peptides of Fas, sFas, and the apoptogen MoAb anti-Fas (CH11) on Fas positive (Jurkat and WC8) and negative (WR19L) cell lines, as variation of the cytoplasmic free $\mathrm{Ca}^{2+}$.

\begin{tabular}{|c|c|c|c|c|c|c|}
\hline & \multicolumn{2}{|c|}{ Jurkat } & \multicolumn{2}{|c|}{ WC8 } & \multicolumn{2}{|c|}{ WR19L } \\
\hline & $\begin{array}{c}\text { Positive } \\
\text { Cells } \\
(\%)\end{array}$ & $\begin{array}{c}\text { Fluorescence } \\
\text { (M) }\end{array}$ & $\begin{array}{c}\text { Positive } \\
\text { Cells } \\
(\%)\end{array}$ & $\begin{array}{c}\text { Fluorescence } \\
\text { (M) }\end{array}$ & $\begin{array}{c}\text { Positive } \\
\text { Cells } \\
(\%)\end{array}$ & $\begin{array}{c}\text { Fluorescence } \\
\text { (M) }\end{array}$ \\
\hline Untreated cells & 2.7 & 4.1 & 4.1 & 3.7 & 3.6 & 3.9 \\
\hline Cells + pept. \# l & 7.7 & 5.6 & 5.3 & 4.6 & 3.8 & 3.7 \\
\hline Cells + VEINCTR-N & 29.1 & 12.7 & 25.6 & 10.3 & 5.3 & 4.1 \\
\hline Cells + pept. \#2 & 12.5 & 8.3 & 10.2 & 7.9 & 4.7 & 2.9 \\
\hline Cells + sFas & 32.6 & 12.3 & 26.1 & 10.4 & 5.8 & 4.0 \\
\hline Cells + CH11 & 29.9 & 11.8 & 23.2 & 11.2 & 3.9 & 3.7 \\
\hline
\end{tabular}

The analysis was completed by flow cytometry $30 \mathrm{~min}$ after staining the pretreated cells with fluo-3, a fluorescent indicator of $\mathrm{Ca}^{2+}$. Data are presented as both percentage of fluo-3 positive cells and mean of fluorescence intensity (M) in each cell preparation. M, mean of fluorescence intensity; sFas, soluble Fas. 


\section{A) Cell membrane Fas-L expression}
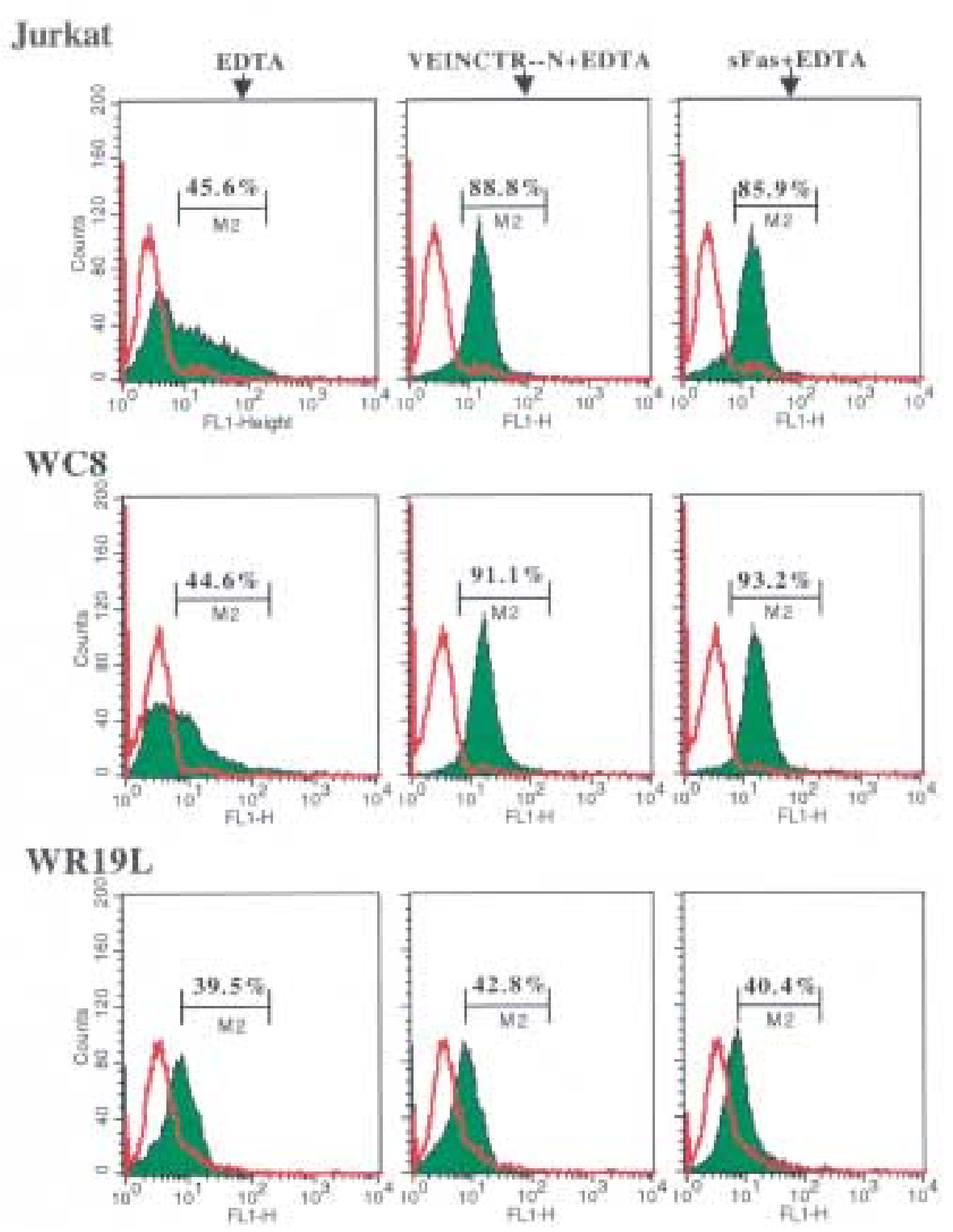

Fig. 3. Induction of Fas-L expression by both VEINCTR-N and sFas. (A) Cytofluorimetric measurement of membrane-bound Fas-L in Jurkat, WC8, and WR 19L cells after treatment with those inhibitors. The cells were incubated in the presence of EDTA to prevent shedding of the ligand by metalloproteinases. Both Jurkat and WC8 almost doubled their Fas-ligand (Fas-L)-positive subsets; whereas, the control Fas-negative WR 19L cells were not influenced. (B) (left graphic) Detection of Fas-L release in supernatants from Jurkat, WC8, and WR 19L cells incubated overnight with $5 \mu \mathrm{g} / \mathrm{ml}$ of soluble Fas (sFas). A significant increase of sFas-L was revealed in culture media from both Jurkat and WC8, compared with untreated control cells $(p<0.02)$, in contrast with the defective response of WR 19L cells. As expected, parallel control cell preparations stimulated by sFas in the presence of EDTA maintained a low level of Fas-L shedding. (right graphic) Measurement of Fas-L mRNA by RT-PCR in Jurkat cells treated with CH11, sFas, and VEINCTR-N. Analysis by the Fluor-S MultiImager gel analyzer confirmed a variable, though significant, Fas-L mRNA increment $(p<0.03)$ in response to the overnight incubation with sFas, VEINCTR-N, or CH11, compared with untreated control cells. By contrast, no difference of $\beta$-actin mRNA expression was observed. O.D., optical density. 


\section{B) Fas-L release in cultures and RT-PCR quantitation}
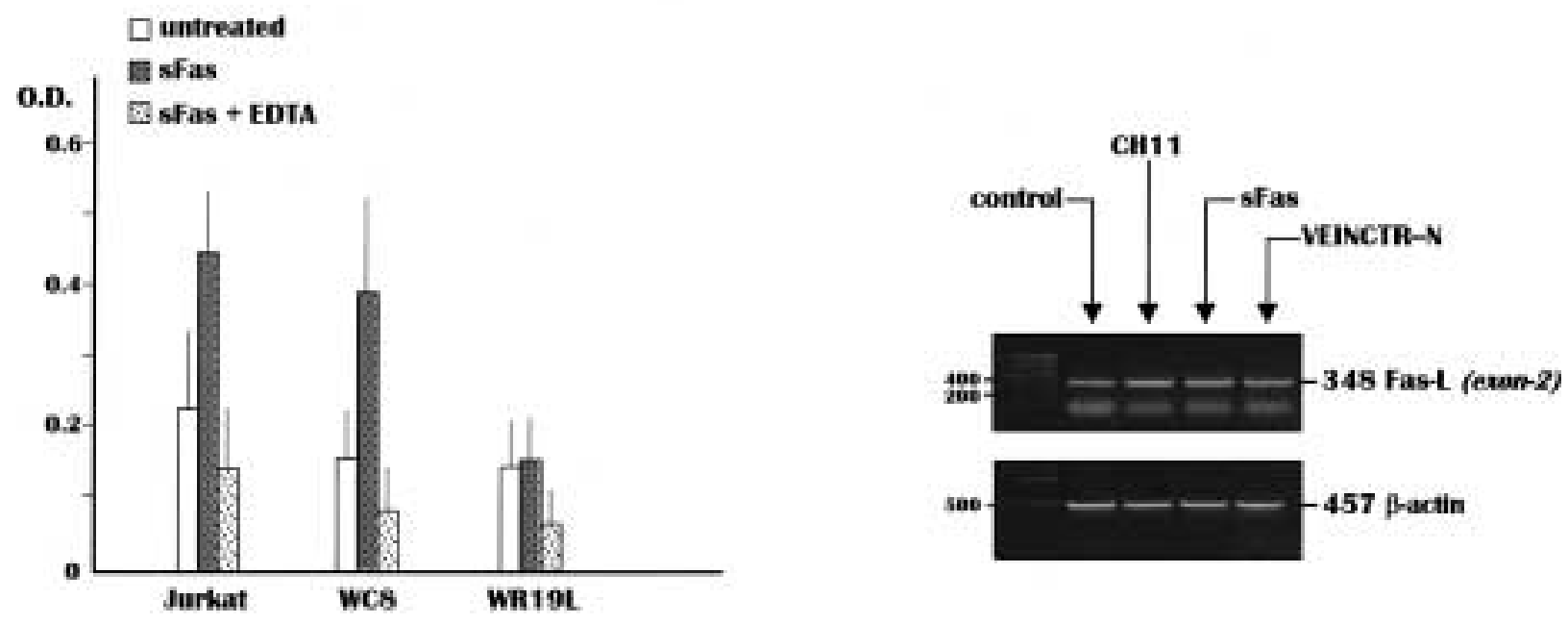

Fig. 3. (Continued)

control cultures showed a moderate release of Fas-L, due to membrane inhibition of sFas- $\mathrm{L}$ shedding. In line with the flow cytometry data, these results emphasized the persistence of Fas-L membrane expression on cells cultured with EDTA and supported the hypothesis that sFas acted as a Fas-L inducer in these cell lines.

Fas-L mRNA measurement in Jurkat cells treated with CHIl, sFas, and VEINCTR-N is illustrated in the right graphic of Figure 3B. When preparing these experiments, we found a different time-course effect in relation to the stimulator used. In particular, $\mathrm{CH} 1 \mathrm{l}$ provided complete induction of apoptosis in T-cell lines within $5 \mathrm{hr}$; whereas, sFas, as well as its peptides, required at least an overnight incubation to obtain an appreciable variation of Fas-L expression. However, measurement of mRNA was completed following treatment with each stimulator. Semiquantitative evaluation by the Fluor-S gel analyzer confirmed the increase of Fas-L expression observed by flow cytometry, since high trace quantity values were detectable in PCR products from cells incubated with either sFas or VEINCTR-N. The linearity of semiquantitative PCR was determined for each condition using graded $(0,0.1 \mu \mathrm{l}, 2,4,8)$ amounts of cDNA (data not shown). The Fluor$S$ trace quantity values in treated cells were 1.607 and 1.438, respectively, compared with 0.891 for the control unstimulated cells. The statistical interpretation of these data suggested that a significant difference occurred be- tween both values of mRNA levels in cells treated with either VEINCTR-N or sFas, compared with unstimulated cells $(p<0.03$ in both instances), though the difference with $\mathrm{CHIl}$ was higher $(p<0.02)$. As expected, the $\beta$-actin used as an internal control of the assay was uniformly expressed by both control and stimulated cells. These results suggested that a variable expression of Fas-L occurred in response to these stimulations.

\section{CPP32 and FLICE are Activated by Both sFas} and VEINCTR-N

Determination of whether the Fas pathway of Jurkat, as a model of Fas-positive T cells, was involved in the apoptosis following the treatment with either sFas or VEINCTR-N was lastly sought by measuring caspase activation in this line. Immunoblotting of the cell extract and semiquantitative measurement of mRNA assessed the expression of caspase 8 (FLICE), which was part of the receptor complex transducing the death signal in response to Fas oligomerization. The activity of caspase 3 (CPP32), which is directly induced by FLICE, and caspase 1 (ICE), which defines activation of the TNF pathway in transduction of the death signal, also was explored. Jurkat cells were separately incubated overnight with sFas, VEINCTR-N, and CHIl MoAb. The cell extracts were used as substrate in immunoblotting. The colorimetric measurement of cleaved 
subunits of both CPP32 and ICE was also assessed in parallel.

We also completed this analysis by the RT-PCR measurement of each caspase mRNA extracted from a parallel set of cell preparations, including a control cell suspension treated with TNF $\alpha$. Results are shown in Figure 4. The chemiluminescence detection of caspases (left graphics) showed a variable expression of their proenzymatic forms. Both sFas and VEINCTR-Ntreated cells were found to express the native caspases, in particular CPP32 and FLICE, at higher intensity than the control cell preparation. We also observed in these cell extracts the
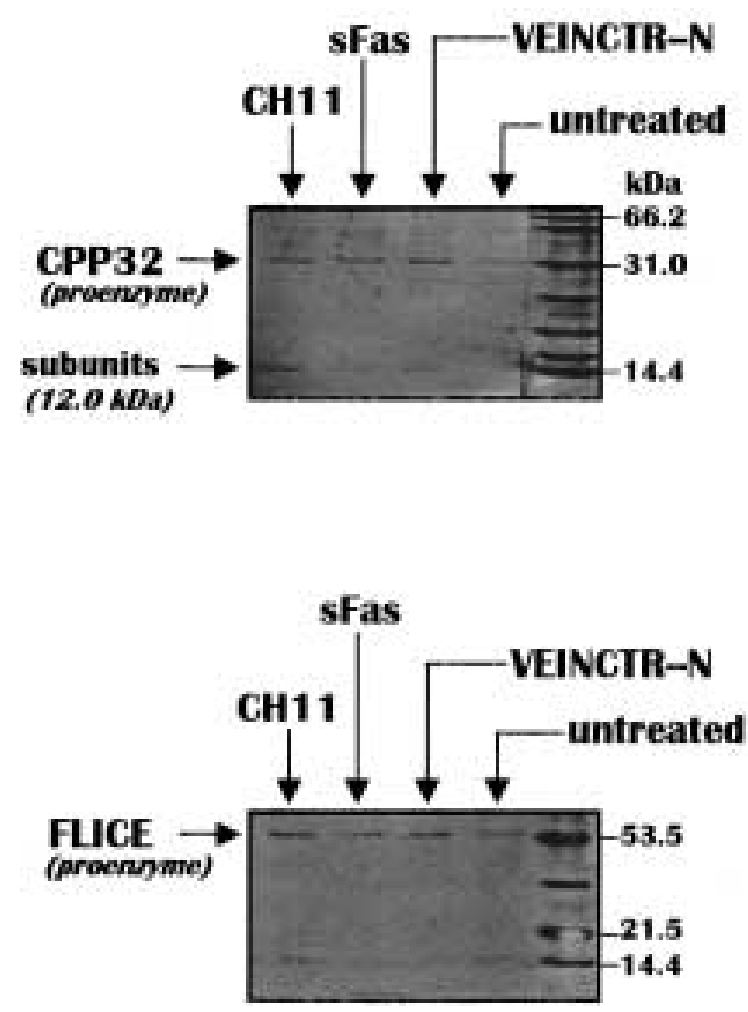

Fig. 4. CPP32 and FLICE expression in Jurkat cells, in response to treatment with sFas and with VEINCTR-N. (Left graphics) Immunoblotting of cell extract shows the increased expression of both CPP32 (upper graphic) and FLICE (lower graphic) and the presence of cleaved CPP32. Rabbit antiserum to CPP32 detected the $12.0 \mathrm{kDa}$ active subunit of that protease in cultures treated with both soluble forms of Fas. Mouse MoAb to FLICE also revealed in these cultures the proenzymatic form in amounts comparable to that induced by $\mathrm{CH} 11$. Control untreated cells showed defective expression of either native or activated enzymes. Numbers refer to molecular weight (m.w.) (Right graphics) - CPP32, FLICE, and ICE mRNA analysis by reverse transcription polymerase chain reaction (RT-PCR) in Jurkat cells incubated with either
$12.0 \mathrm{kDa}$ subunits of CPP32 as expression of its cleaved form, as observed in the CH11supplemented culture. The MoAb to FLICE only revealed the proenzymatic form, since it was unreactive to cleaved subunits. However, an apparent increase of its intensity was recorded in cells treated with either sFas or VEINCTR-N, compared with control untreated cells. By contrast, no evidence of ICE activation was detected on the blotted extracts (data not shown).

RT-PCR (Fig. 4, right graphics) also illustrates the variable expression of both CPP32 and FLICE mRNAs in Jurkat cells treated with sFas
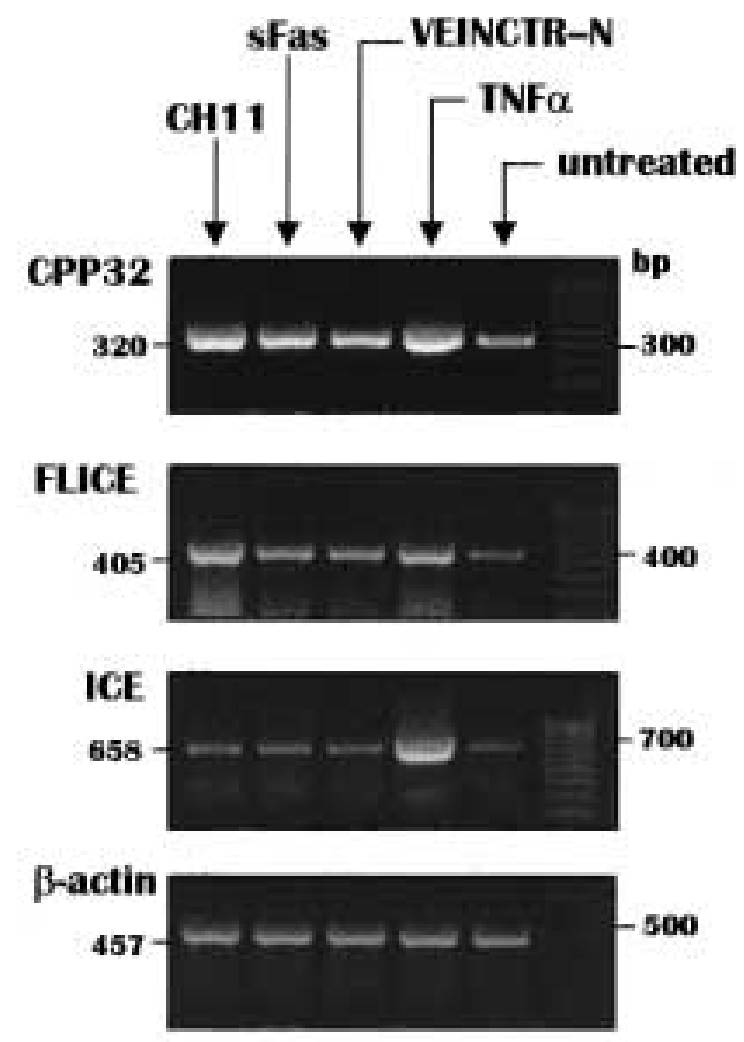

soluble Fas (sFas) or VEINCTR-N, compared with treatment with $\mathrm{CH} 1 \mathrm{l}$ and tumor necrosis factor $\alpha$ $(\mathrm{TNF} \alpha)$. Both CPP32 and FLICE mRNA were expressed variably in cells treated with these soluble forms, compared with the control untreated cells. The semiquantitative Fluor-S evaluation revealed an increase of relative trace quantity values in apparent concordance with those detected in the control cell preparations treated with either $\mathrm{CH} 1 \mathrm{l}$ or $\mathrm{TNF} \alpha$. By contrast, ICE was only expressed by cells supplemented with $\mathrm{TNF} \alpha$, suggesting that suppression of Jurkat cells in cultures treated with either sFas or VEINCTR-N was mediated by their Fas-pathway activation. As expected, the $\beta$-actin expression as internal control, was not influenced. Numbers are bp size. 
Table 2. Absorbance in optical density (O.D.) values at $405 \mathrm{~nm}$ of the enzymatic activity of cleaved isoforms of both caspase 3 and 1 in Jurkat cells.

\begin{tabular}{lcc}
\hline & CPP32 & ICE \\
\hline Untreated & $0.390 \pm 0.072$ & $0.359 \pm 0.019$ \\
Cells + VEINCTR-N & $0.788 \pm 0.068$ & $0.473 \pm 0.052$ \\
Cells + sFas & $0.770 \pm 0.084$ & $0.421 \pm 0.023$ \\
Cells + CH1 & $0.828 \pm 0.052$ & $0.398 \pm 0.061$ \\
Cells + TNF $\alpha$ & $0.807 \pm 0.037$ & $0.889 \pm 0.044$ \\
\hline
\end{tabular}

and VEINCTR-N, compared with positive (CH11 and $\mathrm{TNF} \alpha$ ) and negative (untreated cells) controls. Both caspases apparently were increased with respect to their negative control, though to a lesser extent than in $\mathrm{CH} 1 \mathrm{l}$ and $\mathrm{TNF} \alpha$-treated cultures. The trace quantity values were 2.446 and 2.107 for CPP32, and 1.231 and 1.101 for FLICE. These increases resembled those obtained by the CH11 stimulation (CPP32: 2.547; FLICE: 2.815), suggesting that Fas was activated by the soluble forms of the receptor. By contrast, RT-PCR failed to demonstrate an equivalent activation of ICE. The mRNA related to this protease was not enhanced with respect to the negative control; whereas, it was clearly expressed in the cell preparation supplemented with TNF $\alpha$ (O.D. $\times$ mm: 1.947). The differences obtained by this semiquantitative measurement were in agreement with the values of the reference curves; whereas, the $\beta$-actin control revealed a uniform amplification of relative cDNA in cultures.

Lastly, the presence of cleaved CPP32 in cytosolic extracts of both sFas- and VEINCTR$\mathrm{N}$-treated cells was confirmed by the colorimetric method using pNA-conjugated substrates. Table 2 shows the results in O.D. values at $405 \mathrm{~nm}$. These were almost doubled in cells cultured in the presence of soluble forms of Fas and paralleled the values detected in control assays using either $\mathrm{CH} 11$ or $\mathrm{TNF} \alpha$. Once again, this test failed to prove the presence of activated cleaved subunits of ICE in cells incubated with sFas and VEINCTR-N, thus, providing definite evidence that both soluble molecular forms of Fas were apoptosis-inducers through the Fas pathway.

\section{Discussion}

The present study demonstrates that soluble molecular forms of Fas that include sFas or its major immunodominant domain VEINCTR-N, which are located in a consensus sequence shared by other members of the TNF receptor family, are actual inducers of apoptosis in vitro in peripheral $\mathrm{T}$ cells from both HIV-1-infected patients and controls, as well as in lymphoblastic Fas-positive T-cell lines. These findings lead to reconsidering the biological role of the soluble forms of Fas, whose serologic elevations during the course of HIV-1 infection $(2,9-13)$ and in autoimmune diseases $(17,21$, 22) have been postulated to disable Fas- $L$ of effector cells within the immune system, resulting in down-regulation of apoptosis $(27,29)$.

By using a proliferative assay, we found that most T-cell cultures from HIV-1-infected subjects showing high serum levels of antiVEINCTR-N reactivities and from a control group were significantly inhibited by either sFas or VEINCTR-N. However, the main effect was a clear-cut induction of apoptosis, since the subdiploid DNA-containing cell population was expanded. Similar suppression was also detected in experiments using clonotypic T-cell lines of both human, such as CEM and Jurkat, and mouse origin, namely a WR 19L transformant overexpressing Fas (32). By contrast, the proliferation of Fas-negative cells including K-562, Daudi (40), and WR19L was not affected.

That induction of apoptosis was the predominant element of this suppression also was indicated by overexpression of both a mitochondrial protein detected by the APO2.7 $\mathrm{MoAb}$ as an early apoptosis marker, and annexin-V in Fas-positive cell lines. Since the presence of the membrane-bound form of Fas appeared to be critical in this induction, we investigated the activation of several components along the Fas pathway in both Jurkat and the human Fas-transfected mouse lymphoma WC8, treated with those soluble effectors. Fas- 
L mRNA apparently was up-regulated in both cell lines, since a considerable secretion of the ligand occurred in relative cultures. In addition, immunoblotting of cell extracts and RTPCR of mRNA from Jurkat cells revealed the activation of proenzymatic CPP32 and FLICE and, in several instances, their functional cleaved subunits. These caspases are enrolled in the death-inducing signaling complex (DISC) activated by Fas (41). By contrast, ICE, which is not involved in Fas-mediated apoptosis $(42,43)$, was only detectable in control cells treated in parallel with $\mathrm{TNF} \alpha$. These results also are confirmed by colorimetric assay showing the occurrence of cleaved isoforms of CPP32 in Jurkat cells treated with either sFas or VEINCTR-N. Therefore, the soluble molecular forms of Fas trigger the apoptosis in cells overexpressing the receptor and its shedding by chronically activated or exhausted cells, as in HIV-1 infection, is perhaps a mechanism entrusted with spreading of a death outcome.

Recent studies have emphasized the role of soluble receptors in modulating the functional response of activated cells. Soluble forms of receptors to several interleukins (44-46), granulocyte-macrophage growth factors (47), and TNF $(18,19)$ have been described, but their physiologic roles are still unclear. Soluble HLA class I molecules deliver an apoptotic signal in alloreactive $\mathrm{CD8}^{+} \mathrm{T}$ cells in the absence of a second stimulus interacting with either TCR or CD8 receptors (48). The molecular mechanism implies up-regulation of Fas- $\mathrm{L}$, resulting in the autocrine activation of Fas pathway. It is thought to protect against the rejection of an organ transplant. However, serum sHLA class I and II antigens also may be high in many other conditions associated with the persistent activation of the immune system. The detection of high serum levels of these molecules in HIV-1 disease (49) supports the contention that the autologous down-regulatory mechanism demonstrated in organ recipients is also active during retroviral infection and contributes to the deregulated apoptosis of $\mathrm{T}$ cells. Since we found that the soluble molecular forms of Fas were able to up-regulate both Fas-L expression and release by chronically activated Fas-positive T-cell lines, it is conceivable that induction of apoptosis is mediated by the autocrine stimulation of their own Fas pathway, just as sHLA molecules act in cell lines with a constitutively high expression of Fas (48). We confirmed the occurrence of this mechanism in Jurkat cells incubated with either sFas or its immunodominant epitope by the increase of Fas-L mRNA, and both FLICE and CPP32 activation, including the cleavage in molecular subunits as specifically observed in the Fasmediated transduction of death signals (50). In this context, the detection of ICE mRNA and its cleaved isoform only in TNF $\alpha$-treated Jurkat cells provides a definite proof of the DISC formation in cells undergoing apoptosis in response to either SFas or VEINCTR-N.

A striking question raised by this study is the effective role of these soluble forms of Fas during the chronic immune activation observed in both HIV-1 infection and other diseases, including some autoimmune disorders. Although previous studies have associated alternatively the serologic excess of sFas with early $(2,9)$ or advanced (10-13) HIV-1 infection, and to clinical activation of autoimmune derangements $(17,21,22)$, the full-length receptor and its splicing variants have been seen as essentially apoptosis blockers or downregulators of cell death $(27,29)$. In experimental models using truncated soluble forms of Fas secreted by transfected COS cells (51), their inhibition of apoptosis was ascribed to their ability to block the agonist anti-Fas MoAb by competitive affinity. However, their direct effect on human Fas-positive target cells was not investigated singularly in the absence of the MoAb to Fas. In line with these studies, our results suggest that, besides other regulatory effects, sFas directly interferes with its membrane-bound homologous, resulting in autocrine Fas-L-mediated suppression as a feedback-triggered response. This mechanism had been suspected (51). We now provide evidence of its effectiveness.

An unexpected result of our study is the major suppressive effect induced on Faspositive human and mouse cell lines by the synthetic peptide VEINCTR-N. This effect resembles the immunodominant domain within the highly conserved consensus sequence of Fas. Although to a lesser extent than both fulllength receptor and the prototypic anti-Fas agonist MoAb, the peptide induces sharp signals of apoptosis activation in target cells, such as Fas-L and Fas-related caspases. Intracellular calcium, as a universal second messenger measuring the receptor activity, also is increased by VEINCTR-N in Fas-positive cells, as in cell preparations treated with either sFas or $\mathrm{CH} l 1$. 
The evidence that VEINCTR-N induces Fas activation independent of CD4 activation stems from parallel experiments showing an equivalent apoptogen effect on Jurkat cells by a form of the peptide preincubated with soluble CD4 molecule (data not shown). Therefore, we explain VEINCTR-N-promoted apoptosis as the result of the autocrine Fas-L secretion and/or reverse stimulation of Fas by a mirror molecular mechanism involving peculiar domains of functional receptors $(51,52)$. This interpretation is in agreement with recent studies demonstrating the specific activation of both TNF $\alpha$ and Fas by short peptides homologous to their functional domains $(53,54)$. On the other hand, additional work has documented that apoptosis can be induced directly in either CEM or Jurkat cells by synthetic peptides that are structurally identical to peculiar domains of major histocompatibility complex (MHC) class II and DR antigens, independent of the CD4 engagement (55). In this study, however, the potential activation of Fas-pathway by such peptides was not explored.

Another interesting aspect of this work concerns the significance of anti-VEINCTR-N antibodies in patients with progressing HIV-1 infection and serum elevations of sFas. When we first detected antibodies to VEINCTR-N $(1,3)$, we thought they were elicited by the gp120 V3 loop and became apoptosis effectors following their cross-linkage with the membrane-bound Fas on $\mathrm{T}$ cells. However, the correlation with high levels of sFas, which may also circulate in a structurally degraded form overexposing the immunogenic epitope, supports the hypothesis that reactivities to the full-length and molecular forms of Fas are secreted in response to the high immunogenicity of the receptor. The ability of VEINCTR-N to evoke a cytotoxic response in vitro through Fas in target cells, due to its antigenicity, has been demonstrated by other investigators (56). Although either anti-Fas or anti-VEINCTR-N antibodies are realistic inducers of apoptosis in vitro $(1,2,20)$, it is presently unclear whether they exert a role to neutralize the cytotoxic effect of sFas and its functional domains in vivo.

In conclusion, our data provide a new interpretation for the soluble molecular forms of Fas. Although the shedding of Fas by activated cells is considered a survival mechanism to disable Fas-L-positive effector cells and resist apoptosis, in the first part of this work we found that serum elevations of sFas in HIV-1- infected patients with advanced disease paralleled both the extent of peripheral T-cell apoptosis and titers of anti-VEINCTR-N molecules. Since apoptotic cells genetically are committed to die by an irreversible program, it is conceivable that the release of $s F a s$ is included in that program as a mechanism to amplify the phenomenon by spreading soluble effective forms of the receptor. Although, in our studies the suppressive effect of these molecular soluble forms of Fas are demonstrated in vitro, we believe that a similar amplification event also may occur in vivo, thus explaining the correlation of high levels of sFas with the increased extent of T-cell apoptosis in HIV-1 infection patients. In this context, antibodies to structural domains of Fas would represent an attempt to neutralize molecules involved in a death execution program.

\section{Acknowledgments}

This work was supported by the National AIDS Research Project (1998) of the Italian Ministry of Health, ISS, Rome (Grant \# 9403.40). The authors are indebted with Dr. S. Nagata (Osaka, Japan) for providing cell lines.

\section{References}

1. Silvestris F, Nagata S, Cafforio P, Silvestris N, Dammacco F. (1996) Cross-linking of Fas by antibodies to a peculiar domain of gp120 V3 loop can enhance $\mathrm{T}$ cell apoptosis in HIV-1-infected patients. J. Exp. Med. 184: 2287-2300.

2. Stricker K, Knipping E, Bohler T, Benner A, Krammer PH, Debatin K-M. (1998) Anti-CD95 (APO-1/Fas) autoantibodies and T cell depletion in human immunodeficiency virus type 1 (HIV1)-infected children. Cell Death Differ. 5: 222-230.

3. Silvestris F, Cafforio P, Romito A, Dammacco F. (1994) Molecular specificities of $\mathrm{CD}^{+} \mathrm{T}$ cell reactive IgG and IgM in human immunodeficiency virus (HIV) infection. Clin. Immunol. Immunopathol. 70: 40- 46.

4. Silvestris F, Williams RC, Dammacco F. (1995) Autoreactivity in HIV-1 infection: the role of molecular mimicry. Clin. Immunol. Immunopathol. 75: 197-205.

5. Itoh N, Yonehara S, Ishii A, et al. (1991) The polypeptide encoded by the cDNA for human cell surface antigen Fas can mediate apoptosis. Cell 66: 233-243.

6. Szawlowski PW, Hanke T, Randall RE. (1993) Sequence homology between HIV-1 gp120 and the apoptosis mediating protein Fas. AIDS 7: 1018. 
7. Silvestris F, Cocco $\mathrm{T}$, Cafforio $\mathrm{P}$, Calvani $\mathrm{N}$, Dammacco F. (2000) Immunogenicity of an eight amino-acid domain shared by Fas (CD95/Apo-I) and HIV-1 gp120. I. Structural and antigenic analysis. Molecular Med. 6(6): 494-508.

8. Fadeel B, Lindberg J, Achour A, Chiodi F. (1998) A three-dimensional model of the Fas/APO-I molecule: cross-reactivity of anti-Fas antibodies explained by structural mimicry of antigenic sites. Int. Immunol. 10: 131-140.

9. Fadeel B, Samuelsson A, Hachiya T, Brostrom C, Chiodi F. (1996) Elevated serum levels of soluble Fas/APO-I in human immunodeficiency virus-infected individuals. Blood 89: 4727-4730.

10. Hosaka N, Oyazu N, Kaplan MH, Yagita H, Pahwa S. (1998) Membrane and soluble forms of Fas (CD95) and Fas ligand in peripheral blood mononuclear cells and in plasma from human immunodeficiency virus-infected persons. J. Infect. Dis. 178: 1030-1039.

11. Medrano FJ, Leal M, Arienti D, et al. (1998) Tumor necrosis factor $\beta$ and soluble APO-1/Fas independently predict progression to AIDS in HIV-seropositive patients. AIDS Res. Hum. Retrovirus. 14: 835-843.

12. Jiang JD, Schlesinger $M$, Sacks H, Mildvan D, Roboz JP, Bekesi JG. (1997) Concentrations of soluble CD95 and CD8 antigens in the plasma and levels of $\mathrm{CD}^{+} \mathrm{CD}^{+} 5^{+}, \mathrm{CD}^{+} \mathrm{CD} 38^{+}$, and $\mathrm{CD} 4{ }^{+} \mathrm{CD} 5^{+} \mathrm{T}$ cells are markers for HIV- 1 infection and clinical status. J. Clin. Immunol. 17: 185192.

13. Kamihira S, Yamada Y, Hiragata Y, et al. (1997) Serum levels of soluble Fas/APO-1 receptor in human retroviral infection and associated diseases. Intern. Med. 36: 166-170.

14. Zavazava N, Westphal E, Muller-Rucholtz W. (1991) Characterization of soluble HLA molecules in sweat and quantitative HLA differences in serum of healthy individuals. J. Immunogenet. 17: 387-394.

15. Puppo F, Scudeletti M, Indiveri F, Ferrone F. (1995) Serum HLA class I antigens: Markers or modulators of an immune response? Immunol. Today 16: 124-127.

16. Lake DF, Schluter SF, Wang E, Bernstein RM, Edmundson AB, Marchalonis JJ. (1994) Autoantibodies to the $\alpha / \beta$ T-cell receptors in human immunodeficiency infection: dysregulation and mimicry. Proc. Natl. Acad. Sci. U.S.A. 91: 10849-10853.

17. Nozawa K, Kayagaki N, Tokano Y, Yagita H, Okumura K, Hashimoto Y. (1997) Soluble Fas (APO-1, CD95) and soluble Fas ligand in rheumatic diseases. Arthritis Rheum. 40: 1126-1129.

18. Aukrust P, Liabak NB, Muller F, Lien E, Espevik T, Froland SS. (1994) Serum levels of tumor necrosis factor- $\alpha$ (TNF- $\alpha)$ and soluble TNF receptors in human immunodeficiency virus type 1 infec- tion. Correlation to clinical, immunological and virological parameters. J. Infect. Dis. 169: 420-424. 19. Godfried MH, Van der Poll T, Mulder JW, et al. (1994) Soluble receptors for tumor necrosis factor as predictors of progression to AIDS in asymptomatic human immunodeficiency virus type 1 infection. J. Infect. Dis. 169: 739-745.

20. Prasad NK, Papoff G, Zeuner A, et al. (1998) Therapeutic preparations of normal polyspecific IgG (IVIg) induce apoptosis in human lymphocytes and monocytes: a novel mechanism of action of IVIg involving the Fas apoptotic pathway. J. Immunol. 161: 3781-3790.

21. Knipping E, Krammer $\mathrm{PH}$, Onel KB, Lehman TJA, Mysler E, Elkon KB. (1995) Levels of soluble Fas/APO-1/CD95 in systemic lupus erythematosus and juvenile rheumatoid arthritis. Arthritis Rheum. 38: 1735-1737.

22. Bijl M, van Lopik T, Limburg PC, et al. (1998) Do elevated levels of serum-soluble Fas contribute to the persistence of activated lymphocytes in systemic lupus erythematosus? J. Autoimmun. 11: 457-463.

23. Rore LM, Latchman DS, Isenberg DA. (1997) Elevated soluble Fas production in SLE correlates with HLA status not with disease activity. Lupus 6: 717-722.

24. Tanaka M, Suda T, Haze K, et al. (1996) Fas ligand in human serum. Nature Med. 2: 319-322.

25. Knipping E, Debatin K-M, Stricker K, Heilig B, Eder A, Krammer PH. (1995) Identification of soluble APO-1 in supernatants of human B- and $\mathrm{T}$-cell lines and increased serum levels in B- and T-cell leukemias. Blood 85: 1562-1569.

26. Frassanito MA, Silvestris F, Silvestris N, et al. (1998) Fas/Fas ligand (FasL)-deregulated apoptosis and IL-6 insensitivity in highly malignant myeloma cells. Clin. Exp. Immunol. 114: 179-188.

27. Cheng J, Zhou T, Lin C, et al. (1994) Protection from Fas-mediated apoptosis by a soluble form of the Fas molecule. Science 263: 1759-1762.

28. Suda T, Hashimoto H, Tanaka M, Ochi T, Nagata S. (1997) Membrane Fas ligand kills human peripheral blood T lymphocytes, and soluble Fas ligand blocks the killing. J. Exp. Med. 186: 2045-2050.

29. Papoff G, Cascino I, Eramo A, Starace G, Lynch DH, Ruberti G. (1996) An N-terminal domain shared by Fas/Apo-1 (CD95) soluble variants prevents cell death in vitro. J. Immunol. 156: 4622-4630.

30. Katsikis PD, Wunderlich ES, Smith CA, Herzenberg LA, Herzenberg LA. (1995) Fas antigen stimulation induces marked apoptosis of T lymphocytes in human immunodeficiency virusinfected individuals. J. Exp. Med. 181: 2029-2036.

31. Silvestris F, Cafforio P, Frassanito MA, et al. (1996) Overexpression of Fas antigen on T cells in advanced HIV-1 infection: differential ligation constantly induces apoptosis. AIDS 10: 131-141. 
32. Itoh N, Tsujimoto Y, Nagata Y. (1993) Effect of bcl-2 on Fas-antigen-mediated cell death. J. Immunol. 151: 621-627.

33. Koester SK, Roth P, Mikulka WR, Schlossman SF, Zhang C, Bolton WE. (1997) Monitoring early cellular responses in apoptosis is aided by the mitochondrial membrane protein-specific monoclonal antibody APO2.7. Cytometry 29: 306-312.

34. Vanderberghe PA, Ceuppens JL. (1990) Flow cytometric measurement of cytoplasmic free calcium in human peripheral blood $\mathrm{T}$ lymphocytes with fluo-3, a new fluorescent calcium indicator. J. Immunol. Meth. 127: 197-205.

35. Mariani SM, Matiba B, Baumler C, Krammer PH. (1995) Regulation of cell surface APO-1/Fas (CD95) ligand expression by metalloproteases. Eur. J. Immunol. 25: 2303-2307.

36. Silvestris F, Cafforio P, Camarda G, Tucci M, Frassanito MA, Dammacco F. (1998) Functional Fas-ligand expression on $\mathrm{T}$ cells from HIV-1infected patients is unrelated to $\mathrm{CD}^{+}$lymphopenia. Int. J. Clin. Lab. Res. 28: 215-225.

37. Herr I, Balemans L, Böhler T, Walczak H, Debatin K-M. (1996) Monitoring of CD95 (APO1/Fas) ligand expression in human $\mathrm{T}$ cells by quantitative RT-PCR. Cell Death Diff. 3: 299-305.

38. Molineaux SM, Casano FJ, Rolando AM, et al. (1993) Interleukin 1 beta (IL-1 beta) processing in murine macrophages requires a structurally conserved homologue of human IL-1 beta converting enzyme. Proc. Natl. Acad. Sci. U.S.A. 90: 1809- 1813 .

39. Muzio M, Chinnayan AM, Kischkel FC, et al. (1996) FLICE, a novel FADD-homologous ICE/CED-3-like protease, is recruited to the CD95 (Fas/APO-1) death inducing signalling complex. Cell 85: 817-827.

40. Stohl W, Elliott JE, Li L, Podack ER, Lynch DH, Jacob CO. (1997) Impaired non restricted cytolytic activity in systemic lupus erythematosus: involvement of a pathway independent of Fas, tumor necrosis factor, and extracellular ATP that is associated with little detectable perforin. Arthritis Rheum. 40: 1130-1137.

41. Medema JP, Scaffidi C, Kischkel FC, et al. (1997) FLICE is activated by association with the CD95 death-inducing signalling complex (DISC). EMBO J. 16: 2794-2804.

42. Miwa K, Asano M, Horai R, Iwakura Y, Nagata S, Suda T. (1998) Caspase 1-independent IL-1 beta release and inflammation induced by the apoptosis inducer Fas ligand. Nature Med. 4: 12871292.

43. Chow SC, Slee EA, MacFarlane M, Cohen GM. (1999) Caspase-1 is not involved in CD95/Fasinduced apoptosis in Jurkat cells. Exp. Cell. Res. 246: 491-500.

44. Mosley B, Beckman MP, March CJ, et al. (1989) The murine interleukin-4 receptor molecular cloning and characterization of secreted and membrane bound forms. Cell 59: 335-342.

45. Goodwin RG, Friend D, Ziegler SF, et al. (1990) Cloning of the human and murine interleukin 7 receptors: demonstration of a soluble form and homology to a new receptor superfamily. Cell 60: 941-947.

46. Novick D, Engelmann H, Wallach D, Rubinstein M. (1989) Soluble cytokine receptors are present in normal human urine. J. Exp. Med. 170: 1409-1418.

47. Asworth A, Kraft A. (1990) Cloning of a potential soluble receptor for human GM-CSF. Nucleic Acid Res. 18: 7178-7183.

48. Zavazava N, Krönke M. (1996) Soluble HLA class I molecules induce apoptosis in alloreactive cytotoxic T lymphocytes. Nature Med. 2: 10051010.

49. Filaci, G, Contini P, Brenci S, et al. (1995) Increased serum concentration of soluble HLA-DR antigens in HIV infection and following transplantation. Tissue Antigens 46: 117-123.

50. Peter ME, Kischkel FC, Scheuerpflug CG, Medema JP, Debatin K-M, Krammer PH. (1997) Resistance of cultured peripheral $\mathrm{T}$ cells towards activation-induced cell death involves a lack of recruitment of FLICE (MACH/caspase 8) to the CD95 death-inducing signaling complex. Eur. J. Immunol. 27: 1207-1212.

51. Cascino I, Fiucci G, Papoff G, Ruberti G. (1995) Three functional soluble forms of the human apoptosis-inducing Fas molecule are produced by alternative splicing. J. Immunol. 154: 27062713.

52. Banner D, D'Arcy A, Janes W, et al. (1993) Crystal structure of the soluble human $55 \mathrm{kDa}$ TNF receptor-human TNF-beta complex: implications for TNF receptor activation. Cell 73: 431-445.

53. Boldin MP, Varfolomeev EE, Pancer Z, Mett IL, Camonis JH, Wallach D. (1995) A novel protein that interacts with the death domain of Fas/APOl contains a sequence motif related to the death domain. J. Biol. Chem. 270: 77957798.

54. Boldin MP, Mett IL, Varfolomeev EE, et al. (1995) Self-association of the "death domains" of the p55 tumor necrosis factor (TNF) receptor and Fas/APOl prompts signaling for TNF and Fas/APOl effects. J. Biol. Chem. 270: 387-391.

55. Pugliese O, Boirivant M, Viora M. (1997) Apoptosis induction by human immuno-deficiency virus type 1 (HIV-1) gp120 peptides. Viral Immunol. 10: 95-102.

56. Moukrim Z, Achour A. (1995) Cytotoxic T lymphocytes specific for the synthetic VEINCTR peptide, a sequence found within the Fas molecule and env gp120 in the blood of HIV-1 seropositive individuals. Cell. Mol. Biol. 41: 439444. 